\title{
"MISS DOLLAR": O AMOR IDEALIZADO E O DINHEIRO COMO CAMINHOS PARA A FORMAÇÃO DO PAR AMOROSO
}

\section{NAIARA SANTANA PITA}

Universidade Federal da Bahia

Salvador, Bahia, Brasil

\section{MIRELLA MÁRCIA LONGO VIEIRA LIMA}

Universidade Federal da Bahia

Salvador, Bahia, Brasil

Resumo: Neste estudo do conto "Miss Dollar", analisamos a crítica feita por Machado de Assis à visão idealizada das mulheres contida em romances e poesias oitocentistas. Margarida, muito próxima a uma figura romântica, sofre por amor e pelo pavor de ser amada apenas por seu dinheiro. Na história do seu casamento com Mendonça sobressai a figura da cadelinha Miss Dollar, ali colocada como elemento que promove a ligação do casal. Trata-se de um indicativo de que o convívio entre amor e dinheiro pode não resultar em conflito radical. Ainda que cotejando com o romantismo, sua visão se distancia do dualismo "amor vs. interesse" na formação do par amoroso. Além disso, falamos de como a forma do folhetim pode interferir nas publicações machadianas.

Palavras-chave: Machado de Assis; século XIX; literatura brasileira; folhetim.

\section{"MISS DOLLAR": IDEALIZED LOVE AND MONEY AS PATHWAYS FOR FORMING THE LOVING COUPLE}

\begin{abstract}
In this study, we analyze the critiques made by Machado de Assis regarding the idealized view of women in nineteenth-century novels and poems. Practically a romantic character, Margarida suffers for love and for the dread being loved only for her money. The figure of a little female dog, Miss Dollar, stands out in the story of Margarida's marriage to Mendonça - as an element of connection between the couple. It is a sign that the interaction between love and money may not result in radical conflict. Although compared to romanticism, Machado's view distances him from the "love vs. interest" dualism in forming the loving couple. Additionally, we discuss how the serial novel may interfere with Machadian publications.
\end{abstract}

Keywords: Machado de Assis; nineteenth century; Brazilian literature; serial novel. 
Quando Mendonça disse a Andrade haver escrito a Margarida, o amigo do médico entrou a rir desesperadamente.

- Fiz mal? perguntou Mendonça.

- Estragaste tudo. Os outros pretendentes começaram também por carta; foi justamente a certidão de óbito do amor.

- Paciência se acontecer o mesmo, disse Mendonça levantando os ombros com aparente indiferença; mas eu desejava que não estivesse sempre a falar nos pretendentes; eu não sou pretendente no sentido desses.

- Não querias casar com ela?

- Sem dúvida, se fosse possível, respondeu Mendonça.

- Pois era justamente o que os outros queriam; casar-te-ias e entraria em uma mansa posse dos bens que lhe couberam em partilha e que sobem a muito mais de cem contos. Meu rico, se falo em pretendentes não é por te ofender, porque um dos quatro pretendentes despedidos fui eu.

$-T u$ ?

- É verdade; mas descansa, não fui o primeiro, nem ao menos o último.

- Escreveste?

- Como os outros; como eles, não obtive resposta; isto é, obtive uma: devolveu-me a carta. Portanto, já que lhe escreveste, espera o resto; verás se o que te digo é ou não exato. Estás perdido, Mendonça; fizeste muito mal.

Machado de Assis, "Miss Dollar"

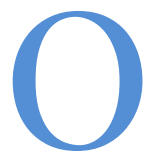

conto "Miss Dollar", de Machado de Assis, foi publicado na coletânea Contos fluminenses no final do ano de 1869, editado pela Livraria Garnier. Além de ser o conto de abertura, é o único dos sete textos que compõem o livro ${ }^{1}$ que não foi publicado primeiramente no Jornal das Famílias - também pertencente a Baptiste-Louis Garnier - durante os anos de 1864 e 1869, como era comum na época. No entanto, embora não tenha passado por essa forma de publicação, "Miss Dollar" apresenta marcas da literatura folhetinesca, tal como ela começou a ser feita no Brasil, a partir da década de 40 do século XIX, sob a influência das publicações francesas e com alguns anos de atraso em relação à França.

\footnotetext{
${ }^{1}$ Os outros contos são: "Luís Soares", "A mulher de preto", "O segredo de Augusta", "Confissões de uma viúva moça", "Linha reta e linha curva" e "Frei Simão".
} 
O nome folhetim é utilizado para as obras que foram publicadas no rodapé dos jornais. Esse espaço era considerado ocioso nos periódicos que começaram a encomendar romances a serem publicados aos poucos, diariamente, para aumentar as vendas, seguindo a tradição francesa. Essa forma de produção atraía os leitores, tornando-os fiéis às histórias, ao mesmo tempo em que atraía os anunciantes. Na França, a publicação em folhetim logo se tornou muito popular, porque já era costume a leitura coletiva e fragmentada de livros. Esse tipo de publicação permitia que as parcelas alfabetizadas das classes trabalhadoras também tivessem acesso à leitura por módicas quantias diárias. Na França, os romances eram um entretenimento diário e uma maneira de atenuar tensões sociais.

No entanto, segundo nos conta Marlyse Meyer, nem todas as narrativas publicadas nos rodapés dos jornais franceses podem ser consideradas romances-folhetins, pois, para isso, a narrativa devia estar cheia de "heróis românticos, mosqueteiros e vingadores, heróis canalhas, mulheres fatais e de sofredoras, de crianças trocadas, raptadas, abandonadas", além de "ricos maldosos e pobres honestos, de peripécias mil" (MEYER, 2005, p. 16). O romance-folhetim chega finalmente a sua boa forma em 1836, com $O$ capitão Paulo, de Alexandre Dumas que já era romancista e dramaturgo aclamado. $\mathrm{O}$ talhe e o sistema folhetinesco inventado por Dumas vai ser reproduzido por inúmeros autores, o que fará com que quase toda produção em prosa seja publicada primeiro em folhetim para depois ser encadernado, da mesma forma como ocorrerá no Brasil:

A fórmula tem outra consequência: uma nova conceituação do termo folhetim, que passa então a designar também o que se torna o novo modo de publicação de romance. Praticamente toda a ficção em prosa da época passa a ser publicada em folhetim, para então depois, conforme o sucesso obtido, sair em volume. É um modo de produção que será também o de Alencar, Macedo, Machado, sem que, no entanto, tais romances sejam forçosamente romances-folhetins. Confusão muitas vezes praticada. É evidente que tal modo de publicação, com suas exigências próprias de cortes de capítulos, de fragmentos que todavia não destruam a impressão de continuidade e totalidade, haveria que influenciar a estrutura de todo romance a partir de então. (MEYER, 1996, p. 63)

Em Paris, o romance-folhetim tem status de produção inferior para as camadas cultas. No entanto, ele era bastante rentável, tanto para os editores dos jornais como para os autores. O que acontece em muitos desses romances 
é que eles eram prolongados ao extremo devido à grande popularidade, o que acabava produzindo, em muitos casos, confusão no enredo e inclusão de elementos desnecessários. Os romances e contos de Machado eram folhetins, mas não romances-folhetinescos como os praticados na França e, embora tenham os acréscimos de gancho entre uma publicação e outra, tais acréscimos costumavam ser suprimidos na versão em livro (BELLIN, 2016, p. $34)$.

Muitos folhetins nacionais eram escritos à moda francesa, mas o que em Paris era uma representação social e de costumes (além de influenciador) era, no Brasil, na maioria dos casos, uma imitação parisiense, ou seja, distante das peculiaridades do país. Os contos longos, novelas, romances de Machado eram publicados semanalmente ou quinzenalmente - mesmo, em alguns casos, a contragosto do autor - em periódicos como na revista feminina $A$ Estação e o já citado Jornal das Famílias.

Nesse contexto de produção, Machado de Assis escreve os seus contos. "Miss Dollar" segue o padrão e também o ironiza, ao narrar o desaparecimento de uma cadelinha galga e apresentar esse incidente como o primeiro passo para a aproximação de duas pessoas. Antes completos desconhecidos, o homem e a mulher se aproximam e acabam por contrair matrimônio. No início do conto, Machado apresenta suposições de quem seria essa Miss Dollar que dá título ao conto (ou romance, nas palavras dele). Na primeira suposição, Miss Dollar seria uma moça "inglesa pálida e delgada" (ASSIS, 1986, p. 27).

Machado dirige-se ao leitor e discursa sobre as suas prováveis expectativas. A primeira imagem de Miss Dollar contém ironia feita ao ideal romântico feminino, em que as mulheres, leitoras de poetas como Tennyson e Camões, alimentam-se pouco, são seres quase transcendentais e falam como o "murmúrio de harpa eólia"; segundo Machado, o amor dessa mulher é "um desmaio, a sua vida uma contemplação, a sua morte um suspiro" (ASSIS, 1986, p. 27).

Os autores citados na construção da primeira hipótese delineiam a escrita que Machado não fará, consciente de sua desconexão com o mundo social que ele pretende representar. Há, portanto, em Machado, ironia e certa dose de reverência aos dois autores, modelos indicativos de uma escrita que diferem de sua escrita. Nem o idealismo amoroso de Camões, nem o sentimento de honra estarão presentes no seu texto. A formação do casal estará longe desses ditames que pertencem a um mundo distante. Consciente da impossibilidade de retratar um contrato conjugal conduzido pelo idealismo e pelo sentimento de moralidade, Machado ironiza. Nesse 
primeiro momento de sua longa trajetória de escritor, sua ironia, ainda leve, traduz reverência e saudade. No entanto, se ainda não há aqui o bisturi machadiano, cortando profundamente para mostrar, no indivíduo, a vitória da miséria humana e, na sociedade, a luta pela sobrevivência - o que resulta sempre em desarmonia -, há já a consciência de que qualquer harmonia, principalmente a amorosa, tem condição subalterna diante dos interesses egoístas e do jogo de interesses sociais. Em outras palavras: o amor feliz é possível se, e somente se, esse amor entra em acordo com ditames inconfessáveis que conduzem de modo sutil o comportamento dos indivíduos e as relações sociais. A crença na possibilidade dessa conjunção está no centro do Romantismo que foi possível a Machado.

O Romantismo como movimento literário e artístico não foi apenas uma tendência estilística, mas uma "emergência histórica, um evento sociocultural" (GUINSBURG, 1978, p. 14), assim como foi também uma expressão do indivíduo. Não há como se pensar num único romantismo. ${ }^{2}$ "Um olhar sonhador, um comportamento evasivo, certo saudosismo e crença de que o mundo já não é tão bom como antes, um intenso e muitas vezes platônico sentimento amoroso" (CITELLI, 1993, p. 9); tudo isso persistiu num primeiro Machado que, no entanto, combinou esses traços com uma profunda consciência da realidade que o circundava. Assim, na segunda hipótese apresentada para a definição de Miss Dollar, entra, em oposição à imagem direcionada pelo idealismo amoroso, um idealismo social. Miss Dollar se torna uma mulher de senso prático, realista, ou matrona que gosta da mesa farta e não se importa com a poesia romântica, "uma robusta americana [...], uma boa mãe de família segundo a doutrina de alguns padresmestres da civilização, isto é, fecunda e ignorante" (ASSIS, 1986, p. 27).

\footnotetext{
2 Movimento cultural de alta complexidade e muitas facetas, o Romantismo é fruto de dois acontecimentos que marcaram a sociedade moderna, a Revolução Francesa e a Revolução Industrial, que acabaram por modificar completamente o equilíbrio das nações. Em seu primeiro momento, na Europa, os artistas românticos apresentam certa revolta com a forma como a aristocracia conduzia a sociedade, a absorção do iluminismo e do liberalismo e pretendiam transformar e redefinir os caminhos da humanidade. No entanto, esse desejo é frustrado com as novas configurações vindas da ascensão da burguesia. Entre essas configurações, delineou-se a possibilidade de ascensão social e a figura do arrivista, disposto a ascender socialmente a qualquer custo e a qualquer preço. Numa sociedade escravocrata, como era a sociedade brasileira do século XIX, era quase impensável a ascensão pelo trabalho. Assim sendo, para o brasileiro restava a esperança de uma herança ou um matrimônio vantajoso. O tema foi abordado também por Alencar, em 1874, no seu célebre romance Senhora. As duas últimas possibilidades aludem ao casamento por interesse, que estará no centro de "Miss Dollar", embora nele receba uma visão irônica que, embora sutil, contém graus de rebaixamento em relação à visão de Alencar. Principalmente, sustentando a possibilidade de confluência entre amor e interesse, Machado não os situa em conflito e menos ainda sustenta a vitória do amor sobre o interesse, tal como faz Alencar.
} 
Machado ironiza figuras femininas e a construção de personagens femininas através da apresentação do que supostamente o leitor teria como expectativa. A surpresa vem da revelação de que Miss Dollar não é uma mulher, mas uma cadela galga (o que é importante ressaltar) que sumiu de casa e tem seu nome colocado em anúncios de dois importantes jornais da época. É oferecida uma recompensa robusta de duzentos mil-réis a quem desse notícias do seu paradeiro. $\mathrm{O}$ anúncio chama a atenção, mas, por mais que seja procurada, a cadela já tinha destino e alojamento na casa do doutor Mendonça. O médico tinha a intenção de ficar com Miss Dollar, mesmo sabendo que o animal possuía um dono, conforme constatou ao ver a inscrição no cadeado preso à coleira. No entanto, colecionador de cães que era, cuidava de Miss Dollar como se fosse sua. O narrador trata de nos convencer sobre a alma sensível de Mendonça, sobre o seu desprezo pelas coisas fúteis e sobre o fato de que ele era um homem que amava os animais e a natureza.

No dia seguinte ao do seu encontro com Miss Dollar, Mendonça vê o anúncio do desaparecimento da cadela e a promessa de recompensa para quem desse notícias do animal. O narrador machadiano usa de ironia para falar da repentina mudança de ânimo de Mendonça, ao ler a nota da recompensa, e alude à sua disponibilidade em ir pessoalmente fazer a restituição, "a sua paixão pelos cães deu-lhe a medida da dor que devia sofrer o dono ou dona de Miss Dollar, visto que chegava a oferecer duzentos milréis de gratificação a quem apresentasse a galga" (ASSIS, 1986, p. 29). Nesse ponto, o narrador manifesta flexibilidade no julgamento da atitude, pois Mendonça não procurou saber quem era o dono da cadelinha antes de ver o anúncio com recompensa no jornal. Como é peculiar a Machado, o feito de Mendonça fica sob um véu de ambiguidade, podendo vir da real consciência de que o animal é importante para alguém. Nesse caso, põe-se no lugar do outro e vai ele mesmo fazer a devolução. Contudo, o montante de duzentos mil-réis tem poder de atração ainda que, conscientemente, Mendonça pense não estar interessado no dinheiro. Vê-se que a tensão entre dinheiro e valor moral já se inicia aí.

Chegando ao endereço indicado no jornal, Mendonça tem pressa em sair. Encontra lá d. Antônia o aguardando e, em seguida, a sobrinha dela, Margarida. O narrador insiste na suposta falta de interesse de Mendonça pelo valor pago pela restituição da cadelinha e anteriormente já indicara que ele, embora fosse um médico formado, só praticava medicina como amador, pois não precisava trabalhar para viver, já que havia ganhado o suficiente para si e para a família. Mendonça havia criado um elixir curativo durante 
uma epidemia que assolara a capital. Esses são indícios suficientes para não lançar suspeita sobre o seu caráter. Ainda assim, parece haver certa dissimulação de sua parte na ansiedade em se retirar da casa, não que estivesse à espera do pagamento do valor prometido, mas porque desejasse continuar travando relações com a recém-conhecida família: "mas, conquanto Mendonça tivesse sumo prazer em estar ali, reparou que era esquisita e humilhante a sua demora. Pareceria estar esperando a gratificação. Para escapar a essa interpretação desairosa, sacrificou o prazer da conversa e a contemplação da moça" (ASSIS, 1986, p. 31).

$\mathrm{Na}$ descrição de Margarida, encontram-se ainda alguns traços românticos, principalmente se levada em conta a comparação feita entre os olhos verdes e a tempestade marítima que tanto assombra Mendonça, a ponto de fazê-lo confessar a um amigo que "se encontrasse um par de olhos verdes fugiria deles com terror" (ASSIS, 1986, p. 31). Mas os olhos parecem atrair mais do que afastar, ideia que também é logo desfeita por uma máxima do amigo. Ao menos no que diz respeito à descrição, os olhos de Margarida podem ser lidos como uma prefiguração dos olhos de ressaca presentes na composição de Capitu. Nesses últimos, prevalece um mistério que Mendonça pretendia decifrar por trás de certa severidade marcante nesse olhar. Essa prevenção foi logo desfeita por um amigo que usou máxima tão convincente quanto a que provocou medo ao médico, "a cor dos olhos não vale nada, a questão é a expressão deles. Podem ser azuis como o céu e pérfidos como o mar" (ASSIS, 1986, p. 32). Vê-se, por esse trecho que, em Mendonça, vivia uma alma romântica, ele já ensaiava uma vida de felicidade junto a Margarida, em que seriam "unidos pelo amor e pela Igreja", viveriam em "uma casa no ermo, olhando para o mar" e beberiam a "taça inteira da celeste felicidade" (ASSIS, 1986, p. 32).

Mais tarde, Mendonça vê as duas senhoras passando num carro. Ao se apresentar a elas, descobre que esse amigo, Andrade - o mesmo do fragmento inicial do texto - as conhece. O médico fica sabendo que Margarida é viúva e que, após a viuvez, recusou casamento a cinco pretendentes sem que houvesse motivo aparente. É lançado assim, por Andrade, o desafio para Mendonça que deve conquistar o coração de Margarida. Mesmo que não explicitamente, descortinam-se os benefícios: amor, vantagem financeira e consideração pública por conseguir conquistar o tão concorrido coração da viúva.

No século XIX, ainda que se tenha criado um novo ambiente, com a transição de um momento de estagnação para um mais dinâmico, com a introdução de novos grupos socioeconômicos, mais complexos, vê-se que o 
casamento continuava sendo imprescindível para o prestígio da mulher no seio da sociedade urbana. Em termos mais objetivos, a mulher que não se casasse estaria fadada à dependência dos pais ou parentes. A mulher solteira não dispunha do poder que a viúva adquiria após a morte do marido, muito menos a possibilidade de continuar nessa condição enquanto não se casasse novamente. À viúva não são necessárias grandes cobranças, já que ela já cumpriu seu dever fundamental como mulher de contrair matrimônio. $\mathrm{Na}$ condição de viúva, ela tem o poder de decidir sobre sua própria vida, a forma de gerir a casa, como utilizar seus bens e com quem vai casar novamente isso se quiser casar. Essa seria uma das razões para Machado escolher esse tipo de mulher para compor personagens fortes e independentes.

No decorrer do conto, Mendonça se torna íntimo e frequentador da casa da família. Quando vê que seus olhares são notados por Margarida, porém não exatamente correspondidos, ele resolve enviar uma carta à viúva. No fragmento citado, ele se encontra à espera da resposta. Durante a conversa que tem com Andrade, Mendonça conhece a desdita dos outros pretendentes com as cartas devolvidas e pede que o amigo não o chame por "pretendente", pois não o era "no sentido desses" (ASSIS, 1986, p. 38). O sentido desse termo é ultrajante para Mendonça, que se sente colocado no posto de "interesseiro" e "bajulador", como os outros. Considerando a ambiguidade dos caracteres machadianos, não podemos excluir que Mendonça esteja realmente apaixonado por Margarida, da mesma forma que não podemos descartar o fato de que uma viúva rica pudesse ser interessante para qualquer homem solteiro da época.

Entretanto, ao contrário do que se esperava, Margarida responde à carta, e o médico, contrariando a vontade dela, decide enviar outra correspondência, mas não obtém resposta. Em seu desespero e ânsia, Mendonça decide ir à casa da família durante a noite. Como encontra o portão do jardim aberto, invade a casa. Estando à espreita, Miss Dollar o reconhece e, mais uma vez, guia-o ao encontro de Margarida que agora está em seu quarto. Dessa forma, Miss Dollar, a cadelinha galga, no primeiro e no segundo momento, é a ponte que leva Mendonça a Margarida. Ela o atraiu à casa de Mata-Cavalos, mas a sua associação com o dinheiro é bastante explícita, "dólar", a moeda. Outra questão diz respeito à escolha de uma cadelinha da raça galgo (e não outra) para "estrelar" esse conto. Galgo é uma raça de animal utilizado para caça e tem como particularidade a velocidade (FERREIRA, 2004, p. 958). Ora, Miss Dollar fez seu serviço. Quando é resgatada por Mendonça, leva um pretendente (futuro marido) para a sua dona, assim como leva o médico para uma noiva com uma incrível fortuna: 
"ao pé de Margarida estava Miss Dollar, que, por esse admirável faro que a natureza concedeu aos cães e aos cortesãos da fortuna, deu dous saltos de alegria apenas viu Mendonça" (ASSIS, 1986, p. 33). Se assim for possível dizer, a cadela prestou um bom serviço aos dois. Também a escolha do sexo do animal de estimação pode ter sido proposital, já que na expressão cadelinha galga, a palavra "galga" pode ter outra conotação além da raça do animal. Galga também é forma do verbo galgar, isto é, "vencer distâncias" - em princípio a que separava os dois namorados. Mas galgar é também "se elevar, subir para um estado mais elevado", "sair do lugar mais baixo para o mais elevado", "chegar em pouco tempo à posição elevada" (AULETE, 1980, p. 1703) - que é o que acontecerá com aquele que se casar com Margarida. Finalmente, galgar é "tomar medidas" e "passar por cima" - que é o que o pretendente precisa fazer para conseguir superar a desconfiança da viúva e o que Mendonça faz ao invadir a casa dela na calada da noite. Portanto, de uma forma ou de outra, a cadelinha, que é caçadora por natureza e traz em sua denominação o dinheiro (dólar), acaba unindo o homem à mulher em vários momentos, vale recapitular: da primeira vez, quando foge de casa; da segunda, quando reapresenta Margarida e Mendonça no eventual encontro na rua do Ouvidor; e na terceira vez, quando Mendonça invade a casa da viúva. Vemos, então, a natureza de psicopompo de Miss Dollar, que a fez conduzir o desconhecido dr. Mendonça à viúva Margarida. ${ }^{3}$

A figura de Miss Dollar tem simbologia dupla na narrativa, primeiro de psicopompo ante Mendonça e Margarida e, segundo, de materialização do dinheiro através de seu nome (Dollar), assim como está duplamente relacionada ao deus grego Hermes. Isso porque Hermes possui várias atribuições dentro do panteão grego - e no romano com o nome de Mercúrio. Hermes aparece na mitologia grega como um dos principais psicopompos junto com Caronte, Apolo e Orfeu -, filho de Zeus e de Maia, e é comumente conhecido como o mensageiro dos deuses, aquele que faz o câmbio entre

\footnotetext{
${ }^{3} \mathrm{O}$ termo psicopompo vem do grego psychopompós, que significa "condutor de almas". Na mitologia, serve como epíteto das divindades que são condutoras das almas entre o mundo dos vivos e o mundo dos mortos. O termo é atribuído principalmente ao deus Hermes que não apenas transita entre os dois mundos, bem como é capaz de "transitar entre as polaridades (não somente a morte e a vida, mas também a noite e o dia, o céu e a terra)" (SAMUELS, 1988, p. 88). O termo ocorre na psicologia para indicar o papel do guia, uma criatura ou entidade que possa conduzir um ser humano a eventos significantes, de descoberta, de transição de percepção. Aparece, em outros momentos da literatura e da mitologia, como animais, pessoas, plantas, material ou organismos. Na mitologia grega, temos o exemplo de Ariadne que ajuda Teseu a se libertar do labirinto de Minotauro. Numa narrativa moderna, temos o Coelho Branco que serve de guia para que Alice chegue ao País das Maravilhas. Isto posto, Miss Dollar é o elo que liga o casal, num evento que seria de menos importância para ambos, sendo assim o psicopompo para o enlace matrimonial.
} 
vários mundos, intérprete e mediador, que promove as trocas e a comunicação; para ele não existem fronteiras, cercas ou fechaduras que não possa transpor, "caracterizado por extrema mobilidade, é símbolo de tudo quanto implica astúcia e ardil", aquele que revela os tesouros e, na sua "função mercurial", promove a transformação da matéria comum em ouro (MENESES, 2010, p. 82). Hermes, assim como Miss Dollar, é o psicopompo, promovendo mutação, ao ligar dois mundos. A sua conexão com o dinheiro está em sua própria natureza. Na sociedade do Rio de Janeiro do século XIX, o dinheiro já revelava o seu papel, circulando entre locais diversos e ligando criaturas de diferentes níveis. São polaridades distantes que se conectam, pela circulação da moeda. A despeito dos padrões anacrônicos do Brasil, já há nele a cidade capitalista, nos quais pessoas que estariam distanciadas se conhecem por força do dinheiro, querendo promover dinâmicas necessárias ao capitalismo; entre elas, o trânsito entre as classes.

Como já vimos, o câmbio entre as classes sociais pode acontecer através do casamento. Mas é necessário ter astúcia e habilidade, pois o dinheiro assim como Hermes - é aquele que promove o mundo da razão em comércio com as forças instintivas. Hermes é também o deus do comércio. Razão essa para que seus atributos sejam usados em negociatas. O século XIX, no Brasil urbano, principalmente na corte, é o período das especulações financeiras, em que as oligarquias, apesar de tentarem adaptar-se aos novos tempos, perdiam espaço e fortunas para os negociadores que ascendiam economicamente através das transações comerciais. Os burgueses e novos ricos possuíam o dinheiro que lhes abria muitas portas (para Hermes "não existem fronteiras, cercas ou fechaduras que não possa transpor" [MENESES, 2010, p. 82]), mas a posse do dinheiro precisava ser acompanhada do status e a melhor forma de adquiri-lo era através de outro negócio: o casamento.

Lembremos, mais uma vez, que Mendonça possuía dinheiro suficiente para si e para a futura família, se desejasse constituí-la, tudo isso através do elixir que curou uma epidemia. Ele transformou sua habilidade médica e a cura de uma doença que estava afetando toda a cidade em ouro, ao conseguir lucrar com isso posteriormente. Para um homem solteiro, bem colocado na vida, restava apenas a constituição de uma família e melhor seria para ele se essa viesse a partir das núpcias com uma herdeira; o que aumentaria as suas posses. Esse fator vem completamente exposto nas falas do amigo de Mendonça.

Andrade serve como uma espécie de alter ego de seu interlocutor, isso porque ele apresenta abertamente situações que, para o próprio Mendonça, 
não estão bem definidas. Nesse caso, como expresso na passagem, percebe-se a relevância de se casar com uma mulher tão rica:

- Pois era justamente o que os outros queriam; casar-te-ias e entrarias na mansa posse dos bens que lhe couberam em partilha e que sobem a muito mais de cem contos. Meu rico, se falo em pretendentes não é por te ofender, porque um dos quatro pretendentes despedidos fui eu. (ASSIS, 1986, p. 38)

O trecho também é a expressão dessa sociedade especulativa que tanto vigorou no século XIX e que negociava status através do casamento, o que não era uma prática nova. Apenas as configurações sociais para que tal ato se desse são diferentes. Grandes mutações foram acontecendo no Rio de Janeiro, durante o final do século XIX, quando fortunas seculares foram transferidas para outras mãos por conta de negociatas escusas, quando a especulação enriquecia uns e arruinava outros, e a "alocação de recursos estatais" (ASSIS, 1986, p. 38) beneficiava aventureiros e especuladores, incentivando um arrivismo feroz.

Personagens como Andrade aparecem em momentos posteriores da obra machadiana como é o caso de Memorial de Aires, em que o Conselheiro vê seu alter ego em outro personagem secundário, d. Cesária - apresentada como cunhada do corretor Miranda e casada com o doutor Farias. Ela tem a peculiaridade de preferir "dizer mal da vida alheia" (ASSIS, 1971, p. 1132) do que jogar o voltarete e o poker como os demais personagens, e o Conselheiro Aires gostava disso, uma vez que, da boca dessa senhora, ele podia ouvir verdades que não encontraria nos demais personagens, principalmente porque a visão da senhora Farias não estava impregnada de uma mentalidade romantizada, mas de um cru senso de realidade. Aires precisava dela para exprimir opiniões que não ousava pôr em termos tão explícitos; quando ousava fazê-los, assumia uma forma branda e com vários jogos irônicos e de ambiguidade, vício que adquiriu em muitos anos de diplomacia.

Em alguns momentos do romance, o Conselheiro chega a louvar a habilidade que Cesária tem em falar mal das pessoas, o mal que ela diz dos outros "é sempre interessante", "esta senhora se não tivesse fel talvez não prestasse; eu nunca a vejo sem ele, e é uma delícia" (ASSIS, 1971, p. 1178) e na frente de todos é sempre tão cortês e amável. Em outro momento, Aires se compara a Cesária, o que comprova que ele reconhecia nela o seu lado mais obscuro, que parecia tão gracioso "nessa honrada senhora", no que ele diz, "como eu, velho maldizente que sou também" (ASSIS, 1971, p. 1165). E é por meio de d. Cesária e de seu marido dr. Farias que ouvimos de forma bastante 
contundente a opinião que o interesse de Tristão por Fidélia não é puramente amoroso.

Fosse como fosse, disse-me que Tristão não voltará tão cedo a Lisboa.

- Sim, concordei, parece que lhe custa muito deixar os padrinhos.

- Os padrinhos? redarguiu Cesária rindo. Ora, conselheiro! Certamente chama assim aos dous olhos da viúva, que são bem ruins padrinhos. Mas lá tem consigo a água benta para o batizado.

Não entendendo, perguntei-lhe que água benta era, e que batizado. $\mathrm{O}$ marido, com a sua rabugem do costume, respondeu que a água benta era o dinheiro, e esfregou o polegar e o índice; ela riu apoiando, e eu compreendi que atribuíam ao moço uma afeição de interesse. (ASSIS, 1971, p. 1166)

O Conselheiro tenta retorquir tais acusações acusando a senhora Farias de invejosa e considerando que suas palavras eram motivadas pelo ódio que sentia, pois, nas palavras dele, Tristão era rico e amava deveras a viúva, mas nada disso chega a afastar a acusação que o casal de conhecidos lança aos noivos e principalmente à viúva, pois "preterida pela política ou preferida pelo dinheiro, tudo é diminuir a outra dama" (ASSIS, 1971, p. 1178).

Como vimos, os alter egos dos personagens principais - Mendonça e Aires - aparecem como reveladores de um ponto de vista que eles queriam encobrir e é dessa forma que eles apresentam a versão de que o dinheiro é um dos grandes atrativos das respectivas viúvas. Entretanto, em ambas as situações, não é possível apregoar, com certeza, se os pretendentes têm interesse no dinheiro delas, da mesma forma que não é possível negar o amor sentido. Um e outro se complementam: a razão do mundo comercial e o sentimento do mundo romântico.

Por diversas vezes, o narrador busca ressaltar que a frequência com que o médico visitava a casa poderia ser um fato socialmente comprometedor para a viúva, pois ela estaria exposta às maledicências. O risco é, todavia, relativizado pela presença de Jorge, uma figura masculina familiar que servia como desculpa para as repetidas visitas. Jorge - filho de d. Antonia - é uma espécie de agregado, bastante comum no universo de Machado. O rapaz é descrito como boêmio, fútil, superficial, ligado às noitadas e frivolidades, descrito por Mendonça como o espírito mais frívolo de toda a cristandade. $\mathrm{O}$ rapaz realiza uma visita a Mendonça para saber sobre a causa de sua ausência na casa da família. Nesse momento, ele revela que a prima passava muito tempo no quarto lendo, como nunca havia feito antes com tanta frequência. Além disso, Margarida era viúva e portanto dotada de algum poder de 
escolha que Mendonça destituiu ao invadir a casa dela. Premida pela necessidade de manter a sua honra e seu prestígio social, restou pouco a escolher; era conveniente aceitar o casamento.

$\mathrm{O}$ casamento era o destino natural das mulheres. E até mesmo uma viúva tinha limitado poder de escolha, pois deveria permanecer atenta, cuidando da sua honra e do seu prestígio social. Na noite em que Mendonça adentra a casa de Margarida, é confrontado por ela, pela situação em que a expunha, como forma de forçar o enlace dos dois:

Foi nesse momento, e só então, que Mendonça reconheceu toda a baixeza do seu procedimento, ou para falar mais acertadamente, toda a alucinação do seu espírito. Pareceu-lhe ver em Margarida a figura da sua consciência, a exprobrar-lhe tamanha indignidade. O pobre rapaz não procurou desculpar-se; a sua resposta foi singela e verdadeira.

- Sei que cometi um ato infame, disse ele; não tinha razão para isso; estava louco; agora conheço a extensão do mal. Não lhe peço que me desculpe, D. Margarida; não mereço perdão; mereço desprezo; adeus!

- Compreendo, senhor, disse Margarida; quer obrigar-me pela força do descrédito quando me não pode obrigar pelo coração. Não é de cavalheiro. (ASSIS, 1986, p. 41)

Depois disso, Mendonça tem tudo como perdido, até que d. Antônia, a tia de Margarida, aparece para contar que sua sobrinha está apaixonada, o que descobriu depois de ler o diário de impressões da viúva. E revela que o motivo de tanta desconfiança se deve ao fato de ter sido infeliz no casamento, porque o falecido marido só tivera interesse em aproveitar sua fortuna. Com essa possibilidade de se expressar livremente, Margarida revela o que sentia: temor de nunca ser amada por si, mas sim por sua fortuna. Sabendo que o mal precisava ser reparado, a moça decide unir o amor que sentia ao ultraje de se ver forçada - por algo que ela supunha que os vizinhos poderiam ter visto, propõe o inevitável casamento. Casam-se. A narrativa abre espaço para a suspeita do cálculo e do cinismo como prática no cotidiano. Como escreve Alfredo Bosi (2003, p. 80) sobre Memorial de Aires, "os apaixonados são mutuamente enganadores e, na exata medida em que sabem trapacear, alcançam a meta dos seus desejos. A casca é idílica, o cerne é realista burguês".

Contudo, com o tempo, Margarida é convencida dos bons sentimentos de Mendonça. Sua boa conduta termina atestando que "a suspeita era gratuita" (ASSIS, 1986, p. 44). Nesses primeiros contos, Machado apenas insinua suspeita de interesse e a encobre, dando ênfase aos bons sentimentos. 
Quando não há mais suspeitas entre os enamorados, o dinheiro parece perder relevância, posto que já desempenhara o seu papel. No desfecho, o casamento é concretizado e Miss Dollar está morta.

\section{Referências}

AUleTe, Caldas; GARCIA, Hamilcar de; NASCENTES, Antenor. Dicionário contemporâneo da língua portuguesa. 3. ed. Lisboa: Delta, 1974-1980; Rio de Janeiro: Primor. v. III.

ASSIS, Machado. Contos Fluminenses. In: Obra completa. Rio de Janeiro: Editora Nova Aguilar, 1986. v. II (Biblioteca luso-brasileira. Série brasileira). . Memorial de Aires. In: Obra completa. Rio de Janeiro: Companhia José Aguilar Editora, 1971. v. I (Biblioteca luso-brasileira. Série brasileira).

BELLIN, Greicy Pinto. Introdução. In: ; SCHMIDT, Ana Lessa. 'Miss Dollar' and other earlystories by Machado de Assis. Hanover: New London Librarium, 2016. p. 18-39.

BOSI, Alfredo. Machado de Assis: o enigma do olhar. São Paulo: Ática, 2003.

CITELLI, Adilson. Romantismo. 3. ed. São Paulo: Ática, 1993. (Série Princípios; 78).

FERREIRA, Aurélio Buarque de Holanda. Novo dicionário Aurélio da língua portuguesa. 3. ed. Curitiba: Positivo, 2004.

GUINSBURG, Jacó. Romantismo, Historicismo e História. In: (Org.) $O$ Romantismo. São Paulo: Perspectiva, 1978.

MENESES, Adélia Bezerra de. Sob o signo de Hermes. Revista Brasileira de Psicanálise, v. 44, n. 3, p. 81-91, 2010. Disponível em: <http:// pepsic.bvsalud.org/scielo.php?pid=S0486-641X2010000300009\&script=sci abstract>. Acesso em: 06 mar. 2017.

MEYER, Marlyse. Folhetim: uma história. 2. ed. São Paulo: Companhia das Letras, 2005.

SAMUELS, A; SHORTER, B; PLAUT, A. Dicionário crítico de análise junguiana. Imago Editora: Rio de Janeiro, 1988.

NAIARA SANTANA PITA é mestre em Literatura e Cultura pela Universidade Federal da Bahia, com dissertação intitulada "Dinheiro, amor e casamento: a formação do par amoroso em Contos fluminenses e Histórias da meia-noite de Machado de Assis". Graduada em Letras Vernáculas com Língua Inglesa pela Universidade Federal da Bahia. 
MIRELLA MÁRCIA LONGO VIEIRA LIMA é doutora em Teoria Literária e Literatura Comparada pela Universidade de São Paulo. Professora Titular de Teoria Literária e Literatura Comparada, atua nos cursos de Graduação e no Programa de Pós-Graduação em Literatura e Cultura do Instituto de Letras da Universidade Federal da Bahia (UFBA). Bolsista nível 2 do CNPq. Publicou Cenas de amor em romances do século XX, Um quarto muito amplo: memorial acadêmico e Confidência mineira: o amor na poesia de Carlos Drummond de Andrade, entre outras publicações. (D) https://orcid.org/0000-0003-41860720 E-mail: mirella@ufba.br

Recebido: 03.12.2018

Aprovado: 04.03.2019 